\title{
What Is the Correct Assignment on Enrolled Patients Receiving Various Doses of Medication in a Study Design?
}

TO THE EDITOR: In the October 2011 issue, Dickman et $\mathrm{al}^{1}$ pointed out that gastroesophageal reflux disease (GERD) patients presenting atypical reflux symptoms, disease duration/severity, Helicobacter pylori infection and obesity etc. were likely responsible to the omeprazole treatment failure. Basically, the purposes of GERD treatment are to heal erosive esophagitis (EE), to ameliorate reflux symptoms (mainly heartburn) and to prevent GERD complications. ${ }^{2}$ However, the effectiveness of proton pump inhibitors (PPIs) to ameliorate heartburn is usually inferior to healing of EE based on the standard dose. For example, non-erosive reflux disease (NERD) is somewhat difficult to treat compared to EE. ${ }^{3,4}$ Treatment failure is a complex issue, and a lot of demographic factors in terms of female patients, weakly acidic reflux, bile reflux, visceral hypersensitivity, concomitant functional bowel disorders, reduced physical and mental health-related quality of life, and inadequate interaction in the health services etc. have been addressed as leading to the treatment failure. ${ }^{2,3,5-7}$ In the literature, treatment failure is well defined as heartburn symptom not adequately responding to twice-daily PPI therapy. ${ }^{2}$ Regarding this publication, several controversial issues need further clarification. First, the patient assignment in study design appears chaotic. According to the effectiveness of the number of omeprazole used, the authors had divided their enrolled subjects into three categories in terms of $\mathrm{A}$ (good to 1 tablet daily), B (failed to 1 tablet daily) and C (failed to 2 tablets daily). Since their GERD patients had been consecutively enrolled, it was unknown who should receive once or twice-daily omeprazole therapy during their assignment and the whole study period. If those patients were acknowledged as good to twice-daily treatment as also defined by the literature, ${ }^{2}$ what category should they be correctly fitted into? Second, endoscopic EE finding constituted $18.0 \%, 51.3 \%$ and $30.4 \%$ among the group A, B and C patients, respectively. Alternatively, it means that the remainders would be either NERD or even Barrett's esophagus (BE). Since the NERD patients are usually more often found than EE counterparts among the epidemiological study, ${ }^{8}$ their treatment result is very likely to mean that NERD patients did show a superior response over EE undergoing PPI treatment.

Unfortunately, this observation is obviously contradictory to the literature, and the authors have not discussed what happened in this event. Finally, BE is not rare in Asia including Israel. ${ }^{9,10}$ This study should also include BE patients during their consecutive enrollment. It is also of interest to know what was the BE impact on PPI therapy in such a large-scaled GERD treatment study.

Full-Young Chang

Division of Gastroenterology, Taipei Veterans General Hospital and National Yang-Ming University School of Medicine, Taipei, Taiwan

1. Dickman R, Boaz M, Aizic S, Beniashvili Z, Fass R, Niv Y. Comparison of clinical characteristics of patients with gastroesophageal reflux disease who failed proton pump inhibitor therapy versus those who fully responded. J Neurogastroenterol Motil 2011; 17:387-394.

2. Kahrilas PJ, Shaheen NJ, Vaezi MF. American Gastroenterological Association Medical Position Statement on the management of gastroesophageal reflux disease. Gastroenterology 2008;135:1383-1391. e5.

3. Fass R, Gasiorowska A. Refractory GERD: what is it? Curr Gastroenterol Rep 2008;10:252-257.

4. Tan VP, Wong WM, Cheung TK, et al. Treatment of non-erosive reflux disease with a proton pump inhibitor in Chinese patients: a randomized controlled trial. J Gastroenterol 2011;46:906-912.

5. Gerson LB, Bonafede M, Princic N, Gregory C, Farr A, Balu S. Development of a refractory gastro-oesophageal reflux score using an administrative claims database. Aliment Pharmacol Ther 2011;34: 555-567.

6. Becher A, El-Serag H. Systematic review: the association between symptomatic response to proton pump inhibitors and health-related 
quality of life in patients with gastro-oesophageal reflux disease. Aliment Pharmacol Ther 2011;34:618-627.

7. Farup PG, Blix I, Førre S, et al. What causes treatment failure - the patient, primary care, secondary care or inadequate interaction in the health services? BMC Health Serv Res 2011;11:111-116.

8. El-Serag HB. Epidemiology of non-erosive reflux disease. Digestion 2008;78(suppl 1):6-10.
9. Jung HK. Epidemiology of gastroesophageal reflux disease in Asia: a systematic review. J Neurogastroenterol Motil 2011;17:14-27.

10. Fireman Z, Wagner G, Weissman J, et al. Prevalence of short-segment Barrett's epithelium. Dig Liver Dis 2001;33:322-325.

\section{Conflicts of interest: None.}

